University of Nebraska - Lincoln

DigitalCommons@University of Nebraska - Lincoln

May 1991

\title{
THE DEPOSITION OF NICKEL BORIDE THIN FILMS BY BORANE AND METALLABORANE CLUSTER COMPOUNDS
}

John A. Glass Jr.

Syracuse University

Shreyas Kher

Syracuse University

Yoon-Gi Kim

Syracuse University

Peter A. Dowben

University of Nebraska-Lincoln, pdowben@unl.edu

James T. Spencer

Syracuse University

Follow this and additional works at: https://digitalcommons.unl.edu/physicsdowben

Part of the Physics Commons

Glass, John A. Jr.; Kher, Shreyas; Kim, Yoon-Gi; Dowben, Peter A.; and Spencer, James T., "THE DEPOSITION OF NICKEL BORIDE THIN FILMS BY BORANE AND METALLABORANE CLUSTER COMPOUNDS" (1991). Peter Dowben Publications. 153.

https://digitalcommons.unl.edu/physicsdowben/153

This Article is brought to you for free and open access by the Research Papers in Physics and Astronomy at DigitalCommons@University of Nebraska - Lincoln. It has been accepted for inclusion in Peter Dowben Publications by an authorized administrator of DigitalCommons@University of Nebraska - Lincoln. 


\section{THE DEPOSITION OF NICKEL BORIDE THIN FILMS BY BORANE AND METAllaborane Cluster COMPOUNDS}

John A. Glass, Jr.*, Shreyas Kher*, Yoon-Gi Kim ${ }^{\dagger}$, P.A. Dowben ${ }^{\dagger}$ and James T. Spencer*

* Deparament of Chemistry and the Center for Molecular Electronics, Syracuse University, Syracuse, New York 13244-4100

$\dagger$ Department of Physics and the Center for Molecular Electronics, Syracuse University, Syracuse, New York 13244-1130

\section{ABSTRACT}

The deposition of high purity and controlled stoichiometry metal boride thin-film materials has recentlv received considerable interest. Borane clusters and their corresponding metal complexes are currently being investigated in our laboratories for their utility as unique source materials for the formation of metallic boride thin films bv MOCVD. Variable composition nickel boride thin films ranging from 0.1 micron to several microns have been prepared. These new materials have been characterized by SEM, AES and XES. The magnetic properties of these new films have been investigated with torque magnetometry and magneto-optic Kerr effect magnetometry.

\section{INTRODUCTION}

The deposition of binary transition metal-main group thin-film materials of controlled stoichiometry is currently an area of intense research interest. Numerous techniques have been studied for the preparation of these materials including molecular beam epitaxy (MBE), sputtering and chemical vapor deposition (CVD) [1]. The control of the stoichiometry in multicomponent films prepared by chemical vapor deposition techniques has relied on varying the ratio of individual source compounds in the vapor phase. These source materials typically deposit at significantly different rates on the substrate at a given temperature, often making the formation of a homogeneous film difficult. The formation of metallic thin-films with varying boron content has recently been explored using the borane polyhedral cluster-assisted deposition process (CAD) [2]. Through the use of this borane cluster chemical transport and deposition process, films ranging in thickness from 0.1 micron to several microns have been readily prepared with controlled composition. This technique has been shown to be generally applicable to the formation of a variety of metal boride materials.

Nickel boride thin films have found a number of important applications not only in traditional uses [3-5], such as hard cutting tools [6] and as inert coatings to protect sensitive devices from severe environmental conditions, but also in areas such as high-energy optical systems [7] and magnetic materials [8-12]. In addition, the incorporation of boron in nickel films has been shown to greatly enhance the strength and hardness of the alloy [13].

Relatively strain-free nickel boride thin films have been reported from the pyrolytic CVD of gaseous mixtures of nickel tetracarbonyl, $\mathrm{Ni}(\mathrm{CO})_{4}$, diborane, $\mathrm{B}_{2} \mathrm{H}_{6}$, and carbon monoxide $[6,14]$ in an argon carrier. $\mathrm{Ni}(\mathrm{CO})_{4}$ and $\mathrm{B}_{2} \mathrm{H}_{6}$ are relatively expensive and extremely toxic and flammable reagents. An alternative to this method which provides stoichiometric control, strain-free films and conformal materials is therefore highly desirable. The cluster-assisted depositional process potentially provides ready solutions to these experimental difficulties while maintaining a vapor phase process with facile stoichiometric control. 
In this paper we report the preparation of a nickel boride film using the cluster assisted depositional (CAD) technique. We also report magnetic measurements on a CAD produced nickel boride thin film using torque magnetometry.

\section{EXPERIMENTAL}

Materials. Decaborane(14) was obtained from the Callery Chemical Company and sublimed under vacuum prior to use. The anhydrous nickel(II)chloride (99\%) and the standard solutions for atomic absorption spectrophotometry were used as received from the Strem Chemical Company and the Aldrich Chemical Company, respectively.

Thin Film Formation. The nickel boride thin film used for the magnetic measurements was made by the application of a vapor phase borane cluster-assisted deposition technique $[2,15]$. In the experiment, using inert atmosphere techniques [16, $1.0 \mathrm{~g}$ (17 mmol) of anhydrous (99\%) nickel(II)chloride was placed in a quartz boat in the quartz reaction chamber, shown in Figure 1. A flask containing approximately $2.0 \mathrm{~g}$ (16 mmol) of

Figure 1. Apparatus for the Preparation of Nickel Boride Thin Films.

To Vacuum System and

Liquid Nitrogen Traps

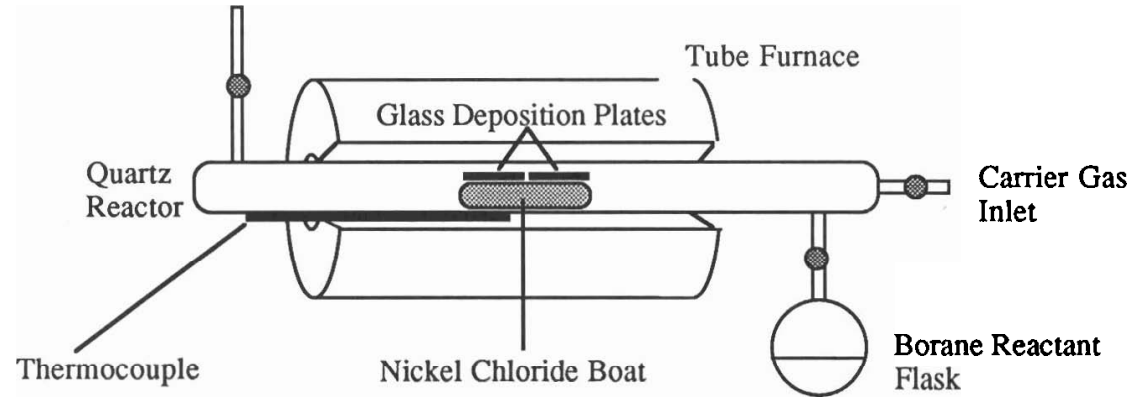

freshly sublimed nido-decaborane(14), $\mathrm{B}_{10} \mathrm{H}_{14}$, was connected to the reactor. The borane reservoir flask was maintained at room temperature during the entire experiment by use of an external constant temperature bath jacketing the flask $\left(21.5^{\circ} \mathrm{C}\right)$. The entire apparatus, including the flask containing the decaborane(14), was evacuated for $15 \mathrm{~min}$., during which time a vacuum of $1 \times 10^{-5}$ Torr was achieved. The stopcock to the decaborane flask was closed and, after $15 \mathrm{~min}$., the reactor was slowly heated to $555^{\circ} \mathrm{C}$ under dynamic vacuum. After obtaining a stable temperature, the stopcock to the decaborane(14) flask was opened to allow a vapor of the borane to pass over the hot $\mathrm{NiCl}_{2}$ while under dynamic vacuum conditions. The unreacted decaborane(14) and other reaction byproducts were trapped downstream in a liquid nitrogen-cooled trap. The deposition was continued for $3 \mathrm{~h}$, during which time a silvery metallic thin film coated the walls of the reactor and the glass deposition plates held above the $\mathrm{NiCl}_{2}$ boat (Figure 1). The stopcock to the borane flask was then closed and the reactor was allowed to cool slowly to room temperature. The reactor was filled with dry nitrogen and the film was removed from the reactor for further study. The film was a metallic, flexible, strong material. The nickel content was determined to be $88.95 \%$ nickel by atomic absorption spectrophotometry. X-ray electron spectroscopic analysis (XES) showed that the film contained no chloride or other heavy element contaminations. Auger electron spectroscopy further showed that the film contained only nickel and boron. Thin films of NiB with nickel contents ranging from $56.6 \%$ to $99.9 \%$ were also readily obtained using this 
method by varying reaction parameters such as temperature and rate of borane flow [15]. A scanning electron micrograph of the NiB film obtained is shown in Figure 4.

It was found in analogous experiments that nido-pentaborane(9), $\mathrm{B}_{5} \mathrm{H}_{9}$, can also be used to form $\mathrm{NiB}$ thin films with $\mathrm{NiCl}_{2}$. While pentaborane(9) has the advantage of being a highly volatile liquid and can therefore be more easily controlled in a flow system than decaborane(14), decaborane(14) has the advantage of being an air-stable material at room temperature while pentaborane $(9)$ reacts violently with air.

Magnetic Measurements. The NiB film was characterized prior to the magnetic measurements by both scanning electron microscopy (SEM) and XES. An incident electron beam of $25 \mathrm{keV}$ was used for both techniques. The thickness of the film was determined by side profile measurements in the SEM. For the XES studies, a SiLi X-ray detector combined with a multichannel analyzer was used to determine the thickness of the film.

The configuration of the torque magnetometer used to measure the magnetic moment of the $\mathrm{NiB}$ film was identical to that previously described [17]. The apparatus is shown in Figures 2 and 3 . The base vacuum was measured at $5 \times 10^{-5}$ Torr prior to the measurements. The NiB film was placed between two glass plates and suspended by a $5 \mathrm{~cm}$ long $0.01 \mathrm{~mm}$ diameter tungsten wire. The glass plates were aligned perpendicular to the direction of the applied field such that the period of oscillation could be measured using a reflected laser beam. Measurements were taken both with and without the $\mathrm{NiB}$ film sandwiched between the glass plates. Oscillation times were measured for the reference, $t_{0}$ (without the NiB film), and sample, $\mathrm{t}_{\mathrm{i}}$ (with the NiB film), at four magnetic field strengths: $900 \mathrm{Oe}, 1300 \mathrm{Oe}, 2000 \mathrm{Oe}$ and 2500 Oe. The data are plotted in Figure 5 as $\frac{1}{R}$ vs. $\frac{1}{H}$ to obtain a slope of 36.667 (CGS).

Figure 2. Torque Magnetometer Vector Diagram.

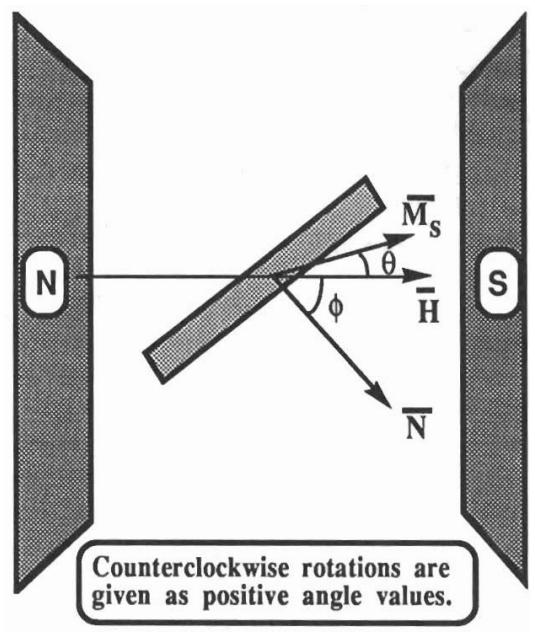

Figure 3. Tube Supporting

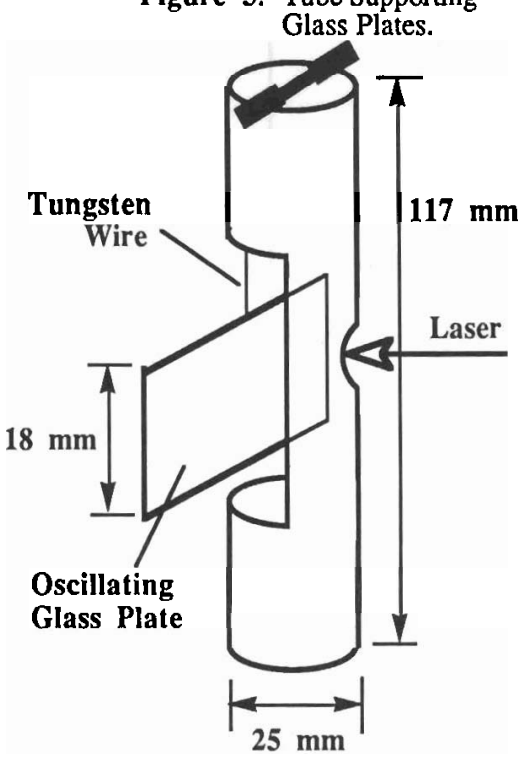


Figure 4. Scanning electron micrograph of a $\mathrm{NiB}$ film deposited at $555^{\circ} \mathrm{C}$ on a copper substrate from anhydrous $\mathrm{NiCl}_{2}$ and Decaborane(14) in vacuum. (88.95\% nickel content)

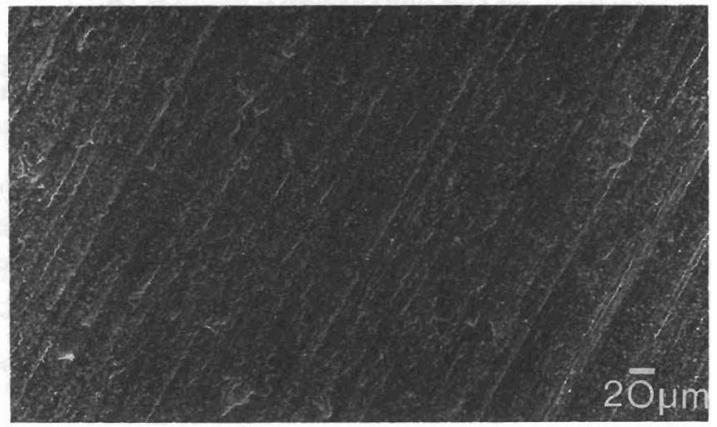

Figure 5. $\frac{1}{\mathrm{R}}$ vs. $\frac{1}{\mathrm{H}}$ for NiB film.

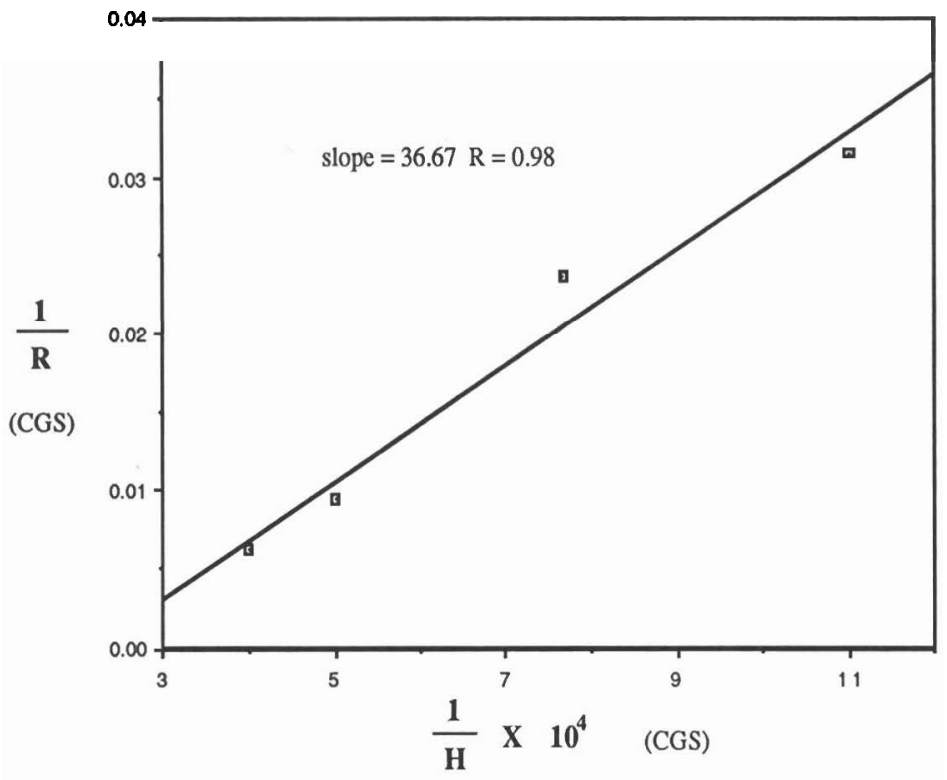

\section{RESULTS AND DISCUSSION}

The $\mathrm{NiB}$ thin films formed from the thermal reaction of $\mathrm{NiCl}_{2}$ with boron hydrides using the cluster-assisted process produces uniform (AES depth profiling [15]), conformal thin film materials. The films can either be formed adhered to various substrates, such as copper, $\mathrm{SiO}_{2}, \mathrm{GaAs}$ or pyrex, or as a substrate-free material. It was possible to control the nickel:boron ratio of the film by controlling reactor temperature, borane flow rate and base vacuum conditions. Nickel contents as high as $99.9 \%$ and as low as $56.6 \%$ have been prepared using this technique. An SEM of a characteristic film is shown in Figure 4. 
The magnetic properties of the nickel boride thin film were determined using a torque magnetometer and applying the Gradmann equation [18]. The magnetic energy of a thin film material in an applied external magnetic field (Figure 2), $\mathrm{H}$, is given by equation (1);

$$
\mathrm{E}(\theta, \varnothing)=-\mathrm{M}_{\mathrm{S}} \mathrm{VH} \cos \theta+2 \mathrm{M}_{\mathrm{S}}^{2} \mathrm{~V} \cos (\theta-\varnothing)+\mathrm{KV} \cos ^{2}(\theta-\varnothing)
$$

where,

$$
\begin{array}{ll}
M_{s}=\text { saturation moment } & \theta=\text { angle between } M_{s} \text { and } H \\
V=\text { volume of the magnetic film } & K=\text { crystal anisotropy constant } \\
\emptyset=\text { angle between } H \text { and the normal to the film }
\end{array}
$$

Let

$$
\begin{aligned}
& \mathrm{L}=2 \pi \mathrm{M}_{\mathrm{S}}{ }^{2}+\mathrm{K} \\
& \mathrm{E}(\theta, \varnothing)=-\mathrm{M}_{\mathrm{S}} \mathrm{VH} \cos \theta+\mathrm{LV} \cos ^{2}(\theta-\emptyset)
\end{aligned}
$$

The position in the oscillation will adjust its direction $\theta_{\mathrm{m}}$ such that a minimum energy condition is achieved.

$$
\begin{aligned}
& \frac{\partial \mathrm{E}(\boldsymbol{\theta}, \emptyset)}{\partial \theta}=\mathrm{M}_{\mathrm{s}} \mathrm{VH} \sin \theta_{\mathrm{m}}-\mathrm{LV} \sin ^{2}\left(\theta_{\mathrm{m}}-\phi\right)=0 \\
& \frac{\partial^{2} \mathrm{E}(\theta, \emptyset)}{\partial \theta^{2}}=\mathrm{M}_{\mathrm{S}} \mathrm{VH} \cos \theta_{\mathrm{m}}-2 \mathrm{LV} \cos ^{2}\left(\theta_{\mathrm{m}}-\emptyset\right)>0
\end{aligned}
$$

If we assume $\theta_{m}$ is small and $\left(\theta_{m}-\emptyset\right)$ is approximately $\frac{\pi}{2}$. Then,

$$
\theta_{m}=\frac{L \pi+2 L \emptyset}{M_{s} H+2 L}
$$

The torque due to the magnetic field is given by

$$
\text { but, } \quad \frac{\mathrm{dEm}(\varnothing)}{\mathrm{d} \emptyset}=\frac{\partial \mathrm{E}}{\partial \theta_{\mathrm{m}}} \frac{\partial \theta_{\mathrm{m}}}{\partial \emptyset}+\frac{\partial \mathrm{E}_{\mathrm{m}}}{\partial \emptyset}
$$

From equations (4), (6), and (8) we obtain

$$
\frac{\mathrm{dEm}}{\mathrm{d} \varnothing}=\frac{\mathrm{M}_{\mathrm{s}} \mathrm{HLV}(\pi+2 \varnothing)}{\mathrm{M}_{\mathrm{s}} \mathrm{H}+2 \mathrm{~L}}
$$

This is the restoring torque due to the magnetic field. Adding the mechanical torque acting on the wire, we obtain the differential equation governing the rotation of the plate.

$$
\mathrm{I} \varnothing=-\mathrm{K}\left(\frac{\pi}{2}+\varnothing\right)-(\pi+2 \varnothing) \frac{\left(\mathrm{M}_{\mathrm{s}} \mathrm{HLV}\right)}{\left(\mathrm{M}_{\mathrm{s}} \mathrm{H}+2 \mathrm{~L}\right)}
$$

where, $\quad K=$ wire torque constant $I \omega_{0}{ }^{2} \quad I=$ moment of inertia of the glass plate $\omega_{0}=$ frequency of rotation of the plate without the film

By rearranging equation (10), we obtain equation (11);

$$
\frac{1}{\mathrm{R}}=\frac{1}{\mathrm{I}\left(\frac{1}{\omega_{\mathrm{i}}^{2}}-\frac{1}{\omega_{0}^{2}}\right)}=\frac{1}{4 \pi^{2} \mathrm{I}\left(\frac{1}{\mathrm{t}_{\mathrm{i}}{ }^{2}}-\frac{1}{\mathrm{t}^{2}}\right)}=\frac{1}{\mathrm{M}_{\mathrm{s}} \mathrm{V}_{\mathrm{i}} \mathrm{H}}+1
$$

where $t_{i}$ is the rotational time of the plate with the NiB film and $V_{i}$ is the volume of the film. Thus a plot of $\frac{1}{R}$ vs. $\frac{1}{H}$ will yield the saturation magnetic moment of the NiB film.

The saturation magnetic moment was obtained from the experimental data plotted in Figure 5 using the calculated thickness of the film as 2.8 microns and equation (12); 


$$
\text { slope }=\frac{1}{M_{s} V}=36.667 \text { (CGS) }
$$

The magnetic moment of the NiB film was calculated to be 81.2 Gauss.

The NiB alloy film was found to be a very soft magnet, thus making it a good candidate for applications as magnetic recording media. $\mathrm{CrO}_{2}$, a common recording medium, has a magnetic saturation of either 470 to $480 \mathrm{G}$ [19] or 326 to $355 \mathrm{G}$ for particles of $0.6 \mu \mathrm{m}$ [20]. Defects may play an important role in determining the magnetic properties of the $\mathrm{NiB}$ films. Mutlu and Aydinuraz [9] have reported that the room temperature susceptibility for large particles of NiB is $1.4 \times 10^{-6} \mathrm{emu} / \mathrm{g}$ but that the susceptibility increases significantly for small particles $(\mathrm{d} \leq 0.23 \mathrm{~mm})$. These differences have been attributed primarily to film defects.

\section{ACKNOWLEDGEMENTS}

We wish to thank the National Science Foundation (Grant No. MSS-89-09793), the U.S. Department of Energy (Award No. DE-FG02-87ER-45319), the Donors of the Petroleum Research Fund administered by the American Chemical Society, the General Electric Company, the Rome Air Development Center (Award No. F30602-89-C-0113), IBM and the Industrial Affiliates Program of the Center for Molecular Electronics for support of this work. We would like to thank K. Schroeder and H. Hejase for their technical assistance.

\section{REFERENCES}

1 P.A. Dowben, J.T. Spencer and G.T. Stauf, Mat. Sci. Eng. B B2, 297 (1989).

2. Z. Zhang, Y.-G. Kim, P.A. Dowben and J.T. Spencer, Mat. Res. Soc. Symp. Proc. 131,407 (1989).

3. R.J Patterson, U.S.Patent, No. 3,499,799 (1970).

4. $\quad$ R.S. Lewandowski, U.S. Patent No. 4,522,849 (1985).

5. L.E. Branovich, W.B.P. Fitzpatrick, M.L. Long, Jr. U.S. Patent No. 3,692,566 (1972).

6. A.W. Mullendore and L.E. Pope, Thin Solid Films 267 (1987).

7. Z. Knittl, Optics of Thin Films, (Wiley and Sons, Publ., New York, 1976).

8. I. Bakonyi, J. Magn. Magn. Mat. 73, 171 (1988).

9. R.H. Mutlu and A. Aydinvraz, J. Magn. Magn. Mat. 68, 328 (1987).

10. N. Lundquist, H.P. Myers and R. Westin, Phil. Mag. 7,1187 (1962).

11. S.N. Kaul and M. Rosenberg, Phys. Rev B25, 5863 (1982).

12. I. Bakonyi, P. Panissod, J. Durand and R. Hasegawa, J. Non-Cryst. Solids $\underline{61 / 62}$, 1189 (1984).

13. A.N. Campbell, A.W. Mullendore, C.R. Hills and J.B. Vandersande, J. Matl. Sci. $\underline{23}, 4049$ (1988).

14. M. Skibo and F.A. Greulich, Thin Solid Films 225 (1984).

15. J.A. Glass, Jr., S. Kher and J.T. Spencer, in preparation.

16. D.F. Shriver, M.A. Drezdzon, The Manipulation of Air-Sensitive Compounds (Wiley-Interscience, New York, 1986).

17. H.J. Hejase, Ph.D. thesis, Syracuse University, 1989.

18. U. Gradmann, Ann. Phys. I, 91 (1961).

19. H.J. Darnell, J. Appl. Phys. 32, 1269 (1961)

20. G. Bate, J. Appl. Phys. 52, 2447 (1981). 